\title{
Pengaruh Corporate Governance, Kepemilikan Asing Dan Audit Tenure Terhadap Integritas Laporan Keuangan
}

\author{
May Wulandari, Erna Hernawati, Husnah Nur Laela Ermaya \\ Universitas Pembangunan Nasional Veteran Jakarta \\ EMail: may.wulandari@upnvj.ac.id
}

Audit, Ownership

Financial

Statement Integrity

339

Submitted:

SEPTEMBER 2020

Accepted:

NOVEMBER 2020

\begin{abstract}
ABSTRAK
Penelitian ini adalah penelitian kuantitatif untuk tujuan mengetahui pengaruh komite audit,komisaris independen, kepemilikan asing dan audit tenure terhadap integritas laporan keuangan. Analisis jalur adalah teknik analisis yang digunakan, software yang digunakan smartpls 3.2.2 5\% dengan tingkat signifikansi. Pengujian menunjukan hasil (1) komite audit berpengaruh negatif terhadap integritas laporan keuangan, (2) komisaris independen tidak mempengaruhi integritas laporan keuangan, (3) kepemilikan asing tidak mempengaruhi integritas laporan keuangan, (4) audit tenure berpengaruh positif terhadap integritas laporan keuangan.
\end{abstract}

Kata Kunci: Komite Audit, Komisaris Independen, Kepemilikan Asing, Audit Tenure, Integritas Laporan Keuangan.

\begin{abstract}
The research is a quantitative research in order to know the influence of audit committee, indepedendent commissioner, foreigh ownership and tenure audit towards financial statements integrity. Path analysis is analytical technique being used, software used is smartpls 3.2 .2 with 5\% level of significance. Testing shows results (1) audit committee gave negative effect to financial statements integrity, (2) independent commissioner gave no effect to financial statements integrity, (3) foreigh ownership also gave no effect to financial statements integrity, (4) tenure audit gave positive effect to financial statements integrity.
\end{abstract}

Keywords: Audit Committee, Independent Commissioner, Foreign Ownership Audit Tenure, Integrity Of Financial Statements.

\section{PENDAHULUAN}

Merefleksikan kondisi keuangan dan hasil usaha suatu entitas dalam masa terpilih merupakan pengertian laporan keuangan (Arista dkk., 2018) dan menjadi alat untuk berkomunikasi antara pihak manajemen dan golongan yang memiliki kepentingan. Yang menyajikan sejauh mana informasi laporan keuangan yang akurat dan terbuka yaitu pengertian laporan dari integritas laporan keuangan (Irawati dan Fakhruddin, 2016).

Seperti contoh kasus adanya dugaan penggelembungan pada beberapa akun dalam laporan keuangan yaitu terjadi pada PT. Tiga Pilar Sejahtera Food, Tbk (AISA) perusahaan pada bidang produksi barang consumer good. Pada waktu (RUPSLB) terdapat bukti direksi lama melaksanakan kenaikan anggaran sebesar Rp 4 triliun dan dugaaan kenaikan pendapatan sebesar Rp 329 miliar pada pos ETIBDA. (Wareza, 2019). Kasus selanjutnya terjadi pada Aliansi Renault-Nissan-Mitsubishi karena adanya dugaan pelanggaran oleh ketua dan CEO perusahaan tesebut yaitu Charlos Ghosn dengan

\section{JIAKES}

Jurnal Ilmiah Akuntansi Kesatuan ol. 8 No. 3,2020 pg. 339-348
IBI Kesatuan ISSN $2337-7852$ E-ISSN 2721 - 3048 
Audit, Ownership Financial Statement Integrity

tuduhan pelaporan kompensasi sedikit, memahami investasi entitas keliru dan penggunaan harta entitas secara privat, Charlos Ghosn juga diduga melanggar instrument keuangan di jepang, dia dicurigai telah melakukan pengecilan penghasilanya pada laporan keuangan (Andebar, 2018).

Untuk meminimalisir kemungkinan adanya tindakan kecurangan, dalam membangun entitas yang efektif dan efisien tata kelola adalah instrumen berharga. Komite audit dan komisaris independen salah satu struktur corporate governance yang mempunyai peran penting dan memiliki posisi yang baik untuk melaksanakan pengawasan didalam internal perusahaan. Faktor yang mempengaruhi integritas laporan keuangan selanjutnya ialah kepemilikan asing yang sahamnya perusahaannya dimiliki shareholder asing (Syamsudin dkk., 2017). Lamanya perikatan perusahaan dengan auditor yang melaksankakan audit laporan keuangan (Audit Tenure) adalah faktor lain yang mempengaruhi integritas laporan.

\section{Tujuan Penelitian}

a. Fakta yang empiris untuk mendapatkan pengaruh tentang komite audit terhadap integritas laporan keuangan.

b. Fakta yang empiris untuk mendapatkan pengaruh tentang komisaris independen terhadap integritas laporan keuangan.

c. Fakta yang empiris untuk mendapatkan pengaruh tentang kepemilikan asing terhadap integritas laporan keuangan.

d. Fakta yang empiris untuk mendapatkan pengaruh tentang audit tenure terhadap integritas laporan keuangan.

\section{Pengembangan Hipotesis}

Komite yang dibuat oleh dewan komisaris agar bertanggungjawab dalam membantu melakukan fungsi dan tugas dewan komisaris merupakan pengertian komite audit, komite audit diketuai oleh komisaris independen (Indrasari dkk., 2016). Corporate governance yang efektif dalam jangka panjang bisa meningkatkan kinerja perusahaan dan menguntungkan bagi pemegang saham, tata kelola perusahaan yang digunakan yaitu komite audit dan komisaris independen (Siahaan., 2017). Komite audit dapat menjadi upaya untuk mengurangi kecurangan pada laporan keuangan sehingga meningkatkan integritas laporan keuangan. Menurut penelitian Qonitin dan Yudowati (2018) menyatakan komite audit berpengaruh negatif terhadap integritas laporan keuangan, Arista dkk. (2018) Kemudian penelitian Pradika dan Hoesada (2019) dan Penelitian dari Istiantoro dkk. (2017) hasil penelitian menyimpulkan bahwa Komite Audit berpengaruh terhadap Integritas Laporan Keuangan. Dari uraian diatas maka peneliti dapat merumuskan hipotesis: H1: Komite Audit Berpengaruh Terhadap Integritas Laporan Keuangan.

Tata kelola yang baik dewan komisaris menerapkan sesuai dengan wewenang dan tanggung jawab berdasarkan peraturan menteri Keuangan Republik Indonesia nomor 88/PMK.06/2015. Kewajiban dan tanggung jawab direksi yang dijalankan dewan komisaris kemudian memberi nasehat kepada direksi. Dewan komisaris membangun arahan dalam pengambilan keputusan, penilaian kinerja, kebijakan pengawasan, wewenang, pembagian tugas, dan tanggung jawab serta melakukannya. Perlindungan pada investor dalam jangka pendek maupun jangka Panjang untuk menentukan kebijakan yang akan dijalankan perusahaan dalam mekanisme tata kelola perusahaan merupakan peran penting yang dimiliki dewan komisaris dan direksi (Wulandari dan Budiartha, 2014). Masalah agensi timbul karena masing-masing pihak berupaya untuk mencapai keinginannya karena ada pemisahan antara agent dan principle berdasarkan teori keagenan. Manajer ingin kepentingannya difasilitasi dengan memberikan dorongan yang besarnya atas hasil kerjanya sedangkan pemegang saham investasi yang di ditanamkan ingin pengembalian yang lebih besar dari sebelumnya, sehingga menimbulkan asymmetry information yaitu dalam mendapatkan kejelasan antara pihak manajemen dan pemilik modal sebagai fisiliator dan penerima informasi yang tidak sebanding. Selain komite audit sistem tata kelola selanjutnya yaitu komisaris independen untuk mengurangi konflik 
keagenan dengan melaksanakan pengawasan, dan bertindak secara independen (Kusmayadi dkk., 2015). Berdasarkan penelitian yang dilakukan oleh Irawati dan Fakhrudin (2016), Kemudian penelitian dari Savitri (2016), Nurdiniah dan Pradika (2017). Dan penelitian Hasanudin (2018) Hasil penelitian menyimpulkan bahwa Komisaris Independen berpengaruh positif terhadap Integritas Laporan Keuangan. Dari uraian diatas peneliti dapat merumuskan hipotesis: H2: Komisaris Independen Berpengaruh Terhadap Integritas Laporan Keuangan.

Kepemilikan asing adalah saham yang dipunyai perusahaan asing pada stakeholder

Audit, Ownership,

Financial

Statement Integrity berasal dari luar indonesia (Syamsudin dkk., 2017). Struktur kepemilikan yaitu kepemilikan asing (eksternal) untuk meningkatkan desakan pada perusahaan untuk mengeluarkan informasi lebih banyak (Malau dan Mulianingsari, 2018). Kepemilikan asing dengan jumlah yang besar dan memiliki hak kontrol dipilih untuk mewakili mekanisme pemantauan eksternal, karena investor institusi asing memiliki kemampuan pemantauan yang unggul dalam meningkatkan transparansi dan hak pemegang saham. Berdasarkan teori agensi kepemilikan asing memiliki potensi untuk mengatasi masalah agensi dari kebijakan Manajerial, meningkatkan kemampuan perusahaan dengan mengurangi penyalahgunaan kekuasaan sehingga meningkatkan kekayaan pemegang saham dan meningkatkan kinerja perusahaan (Yi et al., 2017). Berdasarkan penelitian dari Syamsudin dkk. (2017) menyimpulkan kepemilikan asing berpengaruh negatif terhadap mendeteksi kecurangan laporan keuangan. Dari uraian diatas maka peneliti dapat merumuskan hipotesis:H3: Kepemilikan Asing Berpengaruh Terhadap Integritas Laporan Keuangan.

Ikatan yang lama antara auditor dan klien bisa berkemampuan untuk membangun hubungan yang dekat dan bisa mengurangi independensi auditor dan juga mutu audit. Bahwa lamanya ikatan auditor dan klien bisa membujuk auditor dalam memberikan opini. Oleh karena itu harus dilakukan pergiliran auditor yang bisa meningkatkan mutu audit dalam proses laporan keuangan (Arista dkk., 2018). Pengaruh pada independensi auditor sering dihubungkan dengan Audit tenure, dua faktor yang memicu ikatan yang buruk antara auditor dan klien dengan mutu audit yaitu menurunnya independensi yang timbul dengan berkembangnya ikatan pribadi dan kurangnya daya tampung auditor dalam memberikan pengevaluasian atas kesalahan-kesalahan (Himawan dan Mulianingsih, 2017). Berdasarkan teori keagenan hubungan keterikatan yang lama (Audit Tenure) yaitu auditor dan klien bisa menurunkan sikap independen auditor pada saat melaksanakan pemeriksaan. Berdasarkan penelitian dari Amrulloh dkk. (2016), Prananti (2018) dan Himawan dan Mulianingsih (2017) hasil penelitian menyimpulkan bahwa Audit Tenure berpengaruh positif Terhadap Integritas Laporan keuangan. Dari uraian diatas maka peneliti dapat merumuskan hipotesis: H4: Audit Tenure Berpengaruh Terhadap Integritas Laporan keuangan

\section{METODOLOGI PENELITIAN}

\section{Definisi Operasional Variabel}

Integritas Laporan Keuangan (Y). Laporan keuangan yang menggambarkan keadaan perusahaan yang sesungguhnya dan tidak ada yang dirahasiakan adalah integritas laporan keuangan (Hardiningsih, 2010). penelitian ini menggunakan pengukuran konservatisme, pengukuran konservatisme berdasarkan metode Givoly dan Hayn (2000):

Keterangan:

$$
C O N_{\downarrow} A C C=N I_{i t}-C f o
$$

CON_ACC: tingkat konservatisme akuntansi

$\mathrm{NI}_{\text {it }} \quad$ : Net income + depresiasi i pada tahun $\mathrm{t}$

$\mathrm{CFo}_{\text {it }} \quad$ : arus kas dari kegiatan operasi perusahaan i pada tahun $\mathrm{t}$

Komite Audit. Komite yang dibuat oleh dewan komisaris agar bertanggungjawab dalam membantu melakukan fungsi dan tugas dewan komisaris merupakan pengertian komite audit, komite audit diketuai oleh komisaris independen (Indrasari dkk., 2016). Komite audit diukur dengan menggunakan jumlah komite audit dibagi keseluruhan 
Audit, Ownership

Financial

Statement Integrity dewan (direksi + komisaris), Eksandy (2017) dan Miko dan Kamardin (2015) dengan pengukuran sebagai berikut:

$$
\text { Komite Audit }=\frac{\text { Jumlah komite audit }}{\text { keseluruhan dewan }(\text { direksi }+ \text { komisaris })}
$$

Komisaris Independen. Anggota dewan komisaris yang berasal dari luar sebuah badan dalam entitas yaitu komisaris indepenen. (Arista dkk., 2018). Pengukuran komisaris independen penelitian ini diukur memakai kompetensi dewan komisaris (Octosiva dkk., 2015). Dengan menggunakan pengukuran sebagai berikut:

Jumlah dewan komisaris yang memiliki pengalaman

$$
K I S=\frac{\text { bekerja di industri utama perusahaan beroperasi }}{\text { Jumlah dewan komisaris }} \times 100 \%
$$

Kepemilikan asing adalah saham yang dipunyai perusahaan asing pada stakeholder berasal dari luar indonesia (Syamsudin dkk., 2017). Kepemilikan asing diukur dengan persentase saham yang dipegang oleh entitas bisnis, individu dan Institusi asing dibandingkan dengan total saham yang beredar (Malau dan Mulianingsih, 2018).

Audit Tenure Lamanya waktu seorang auditor yang bekerja dalam suatu perjanjian merupakan Audit Tenure (Qoyyimah dkk., 2015). Audit Tenure diukur dengan menghitung lamanya perikatan antara auditor (partner) dengan klien (Arista dkk., 2018).

\section{Populasi, Sampel, dan Metode}

Populasi dalam penelitian ini adalah Perusahaan manufaktur yang menerbitkan laporan keuangan tahunan (Annual Report) penelitian ini dilakukan mulai 2016-2018 selama 3 tahun periode. Pengambilan sampel dalam penelitian ini menggunakan purposive sampling (Siregar 2017, hlm.33). Data yang dipakai dapat diakses melalui website resmi Bursa Efek Indonesia (BEI) www.idx.co.id dan website masing-masing entitas. Teknik analisis data dalam penelitian ini yaitu structural equation model (SEM) menggunakan aplikasi Smart Partial Least Square (PLS) version 3.2.2.

\section{HASIL DAN PEMBAHASAN \\ Analisis Statistik Deskriptif}

\begin{tabular}{|c|c|c|c|c|c|c|c|}
\hline $\begin{array}{l}\text { Delimiter: } \\
\text { Value Quote Cl } \\
\text { Number Forma } \\
\text { Missing Value } 1\end{array}$ & $\begin{array}{l}\text { Iracter: } \\
\text { : } \\
\text { arket: }\end{array}$ & $\begin{array}{l}\text { Semicolon } \\
\text { None } \\
\text { US (Examp } \\
\text { None }\end{array}$ & $1.000,23)$ & & $\begin{array}{l}\text { conding } \\
\text { nple Size } \\
\text { icators } \\
\text { ssing Values }\end{array}$ & $\begin{array}{l}: \text { UTF-8 } \\
: 144 \\
: 5 \\
: 0\end{array}$ & \\
\hline Variabel & Missing & Mean & Min & Max & $\begin{array}{l}\text { Standar } \\
\text { Deviasi }\end{array}$ & $\begin{array}{c}\text { Excess } \\
\text { Kurtosis }\end{array}$ & Skewness \\
\hline $\begin{array}{l}\text { Integritas } \\
\text { Laporan } \\
\text { Keuangan } \\
\text { CONACC }\end{array}$ & 0 & $\begin{array}{c}40770302 \\
775.278\end{array}$ & $\begin{array}{c}- \\
2179880000 \\
00.000\end{array}$ & $\begin{array}{l}43991623 \\
4452.000\end{array}$ & $\begin{array}{l}10909296 \\
5833.827\end{array}$ & 1.079 & 0.786 \\
\hline $\begin{array}{l}\text { Komite } \\
\text { Audit }\end{array}$ & 0 & 0.371 & 0.130 & 0.667 & 0.124 & -0.688 & 0.030 \\
\hline $\begin{array}{l}\text { Komisaris } \\
\text { Independen }\end{array}$ & 0 & 0.877 & 0.333 & 1.000 & 0.193 & 1.030 & -1.445 \\
\hline $\begin{array}{l}\text { Kepemilikan } \\
\text { Asing }\end{array}$ & 0 & 0.430 & 0.002 & 1.000 & 0.336 & -1.341 & 0.235 \\
\hline Audit Tenure & 0 & 1.306 & 1.000 & 3.000 & 0.504 & 0.782 & 1.338 \\
\hline
\end{tabular}

Tabel 1. Hasil Statistik Deskriptif Integritas Laporan Keuangan

Sumber: Data Diolah dengan PLS Versi 3.2.2

Model Pengukuran (Outer Model)

Tabel 2. Outer VIF Values

\begin{tabular}{llll} 
Variabel & VIF & Variabel & VIF \\
$\mathrm{X} 1$ & 1.000 & $\mathrm{X} 4$ & 1.000 \\
\hline $\mathrm{X} 2$ & 1.000 & $\mathrm{Y}$ & 1.000 \\
\hline $\mathrm{X} 3$ & 1.000 & &
\end{tabular}

Sumber: Data Diolah dengan PLS Versi 3.2.2 
Berdasarkan tabel hasil outer VIF values bahwa hasil nilai VIF $<10$. Berarti seluruh variabel didalam penelitian ini adalah valid atau tidak terjadi multikolinearitas.

Model Struktural (Inner Model)

R-Square

Tabel 3. R-square

\begin{tabular}{ll}
\hline Kontruk & R-Adjusted Square \\
\hline Integritas Laporan Keuangan (Y) & 0.105 \\
\hline
\end{tabular}

Sumber: Telah Diolah dengan PLS Versi 3.2.2

Berdasarkan tabel 3 nilai $R$-square untuk integritas laporan keuangan (Y) menunjukan nilai sebesar 0.105 oleh karena itu bisa disimpulkan maka variabel independen yaitu komite audit (X1), komisaris independen (X2), kepemilikan asing (X3) dan audit tenure (X4) dapat menjelaskan variabel dependen yaitu integritas laporan keuangan (Y) adalah sejumlah $10,5 \%$ dan selebihnya $89,5 \%$ dipaparkan oleh variabel lain diluar yang diteliti.

\section{Q-Square}

Dalam uji $Q$-square pada model struktrural (Inner Model) untuk mengukur sejauh mana nilai observasi dari nilai $Q$-square dalam mengestimasi parameternya. Nilai $\mathrm{Q}^{2}>0$ maka membuktikan model memiliki predictive relevance, dan jika nilai $\mathrm{Q}^{2}<0$ maka menunjukan bahwa model kurang mempunyai predictive relevance. Untuk kalkulasi $Q$-square sebagai berikut: $\mathrm{Q}^{2}=1-(1-0.105)=0.105$

Analisis Jalur

Tabel 4. Path Coefficients

\begin{tabular}{|c|c|c|c|c|c|}
\hline Konstruk & $\begin{array}{l}\text { Komite } \\
\text { Audit } \\
\text { (X1) }\end{array}$ & $\begin{array}{c}\text { Komisaris } \\
\text { Independen } \\
\text { (X2) }\end{array}$ & $\begin{array}{c}\text { Kepemilikan } \\
\text { Asing (X3) }\end{array}$ & $\begin{array}{l}\text { Audit Tenure } \\
\text { (X4) }\end{array}$ & $\begin{array}{c}\text { Integritas } \\
\text { Laporan } \\
\text { Keuangan } \\
(Y)\end{array}$ \\
\hline Komite Audit (X1) & & & & & -0.182 \\
\hline $\begin{array}{l}\text { Komisaris } \\
\text { Independen (X2) }\end{array}$ & & & & & -0.132 \\
\hline $\begin{array}{l}\text { Kepemilikan Asing } \\
\text { (X3) }\end{array}$ & & & & & -0.073 \\
\hline Audit Tenure (X4) & & & & & 0.287 \\
\hline
\end{tabular}

Audit, Ownership,

Financial

Statement Integrity

343

Sumber: Data Diolah dengan PLS Versi 3.2.2

Berdasarkan tabel path coefficients yang telah disajikan diatas hasil koefisien analisis jalur variabel komite audit terhadap integritas laporan keuangan yaitu sejumlah -0.182 terdapat hubungan yang negatif, hasil analisis jalur variabel komisaris independen terhadap integritas laporan keuangan yaitu sejumlah -0.132 terdapat hubungan yang negatif, hasil analisis jalur variabel kepemilikan asing terhadap integritas laporan keuangan yaitu sejumlah -0.073 terdapat hubungan yang negatif, hasil analisis jalur variabel audit tenure terhadap integritas laporan keuangan yaitu sebesar 0.287 terdapat hubungan yang positif.

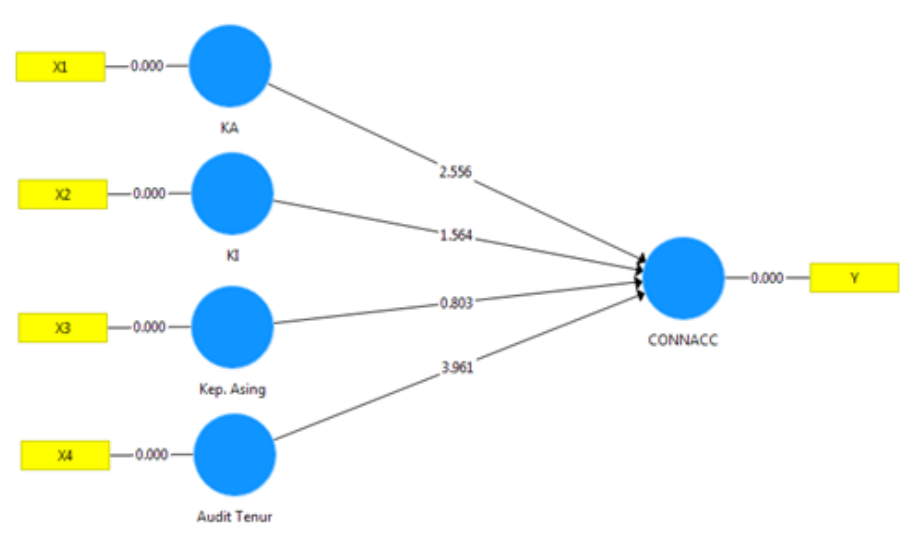

Gambar 1. Inner Model 
Audit, Ownership

Financial

Statement Integrity
Uji Hipotesis

Tabel Path 5. Coefficients uji t-statistik

\begin{tabular}{lccccc}
\hline & $\begin{array}{c}\text { Original } \\
\text { Sample (O) }\end{array}$ & $\begin{array}{c}\text { Sample } \\
\text { Mean (M) }\end{array}$ & $\begin{array}{c}\text { Standar } \\
\text { Deviation } \\
\text { (STDV) }\end{array}$ & t Statistik & P Values \\
\hline KA > CONACC & -0.182 & -0.184 & 0.071 & 2.556 & 0.011 \\
\hline KI > CONACC & -0.132 & -0.134 & 0.085 & 1.564 & 0.119 \\
\hline $\begin{array}{l}\text { KEP.Asing }> \\
\text { CONACC }\end{array}$ & -0.073 & -0.077 & 0.091 & 0.803 & 0.422 \\
\hline $\begin{array}{l}\text { Audit Tenure }> \\
\text { CONACC }\end{array}$ & 0.287 & 0.283 & 0.073 & 3.961 & 0.000 \\
\hline
\end{tabular}

Sumber: Data Diolah dengan PLS Versi 3.2.2

Variabel komite audit terhadap integritas laporan keuangan memiliki angka $t_{\text {hitung }} 2.556$ sedangkan nilai $t_{\text {tabel }}$ sebesar 1.96 sehingga dapat diketahui bahwa $t_{\text {tabel }}>t_{\text {hitung. }}$. Selanjutnya untuk tingkat signifikansi variabel komite audit sejumlah 0.011 lebih kecil dari tingkat signifikansi $0.05(0.011<0.05)$ dengan demikian $\mathrm{H}_{\mathrm{a}}$ diterima dan $\mathrm{H}_{\mathrm{o}}$ ditolak maka variabel komite audit berpengaruh terhadap integritas laporan keuangan.

Variabel komisaris independen terhadap integritas laporan keuangan berdasarkan tabel menunjukan $t_{\text {hitung }} 1.564$ sedangkan nilai $t_{\text {tabel }} 1.96$ sehingga dapat diketahui bahwa $\mathrm{t}_{\text {tabel }}<\mathrm{t}_{\text {hitung. }}$. Selanjutnya untuk tingkat signifikansi variabel komisaris independen sejumlah 0.119 lebih besar dari $0.05(0.119>0.05)$ dengan demikian $\mathrm{H}_{\mathrm{a}}$ ditolak $\mathrm{H}_{\mathrm{o}}$ diterima maka variabel komisaris independen tidak berpengaruh terhadap integritas laporan keuangan.

Variabel kepemilikan asing terhadap integritas laporan keuangan berdasarkan tabel menunjukan $t_{\text {hitung }} 0.803$ sedangkan nilai $t_{\text {tabel }}$ sebesar 1.96 sehingga dapat diketahui bahwa $\mathrm{t}_{\text {tabel }}<\mathrm{t}_{\text {hitung. }}$ Selanjutnya untuk tingkat signifikansi varaibel kepemilikan asing sebesar 0.422 lebih besar daripada $0.05(0.422>0.05)$ dengan demikian $\mathrm{H}_{\mathrm{a}}$ ditolak $\mathrm{H}_{\mathrm{o}}$ diterima maka variabel kepemilikan asing tidak berpengaruh terhadap integritas laporan keuangan.

Variabel audit tenure terhadap integritas laporan keuangan memiliki $t_{\text {hitung }} 3.961$ sedangkan nilai $t_{\text {tabel }} 1.96$ sehingga dapat diketahui bahwa $t_{\text {tabel }}>t_{\text {hitung. }}$. Selanjutnya untuk tingkat signifikansi variabel audit tenure sejumlah 0.000 lebih kecil dari tingkat signifikansi $0.05(0.000<0.05)$ dengan demikian $\mathrm{H}_{\mathrm{a}}$ diterima dan $\mathrm{H}_{\mathrm{o}}$ ditolak maka audit tenure berpengaruh terhadap integritas laporan keuangan.

\section{Pengaruh Komite Audit Terhadap Integritas Laporan Keuangan}

Peraturan OJK Nomor 3/PJOK.05/2014 pasal 28 ayat 3 mengenai tata kelola yang baik untuk perusahaan pembiayaan bahwa komite audit dibuat untuk mengawasi dan memeriksa efektifitas sistem pengendalian internal dan pelaksanaan tugas auditor internal dan auditor eksternal dengan melaksanakan pengawasan dan penilaian atas perancangan dan penerapan audit dalam bentuk penilaian kelengkapan pengendalian internal dalam mengakomodasi dewan komisaris termasuk proses laporan keuangan, komite audit bisa menjadi cara meminimalisir kecurangan atas informasi akuntansi agar meningkatkan integritas laporan keuangan (Arista dkk., 2018). Hasil penelitian ini juga didukung oleh teori agensi menyatakan bahwa sistem corporate governance perusahaan yang efisien dapat meminimalisir konflik agensi antara agent dan principle yang mengarah pada manipulasi yang dilakukan oleh manajemen (Shan et al., 2013).

Mekanisme corporate governance seperti komite audit untuk perusahaan dalam pengendalian internal, menentukan mutu laporan keuangan, dan menaikan efektifitas fungsi audit dalam mendukung pembuatan pengendalian internal yang baik dan membarui kualitas keterbukaan. Penelitian yang dilakukan oleh Qonitin dan Yudowati (2018) menyatakan komite audit berpengaruh negatif terhadap integritas laporan keuangan, Arista dkk. (2018), Pradika dan Hoesada (2019), dan Istiantoro dkk. (2017) selaras dengan penelitia ini yang menunjukan bahwa komite audit berpengaruh terhadap integritas laporan keuangan. 

berhubungan komisaris independen yang tidak memiliki pengalaman sehingga kurang optimal dalam melaksanakan pengawasan. Dewan komisaris sebagai bagian entitas berfungsi dan bertanggungjawab secara bersama-sama dalam melaksanakan pemantauan dan memberikan arahan kepada direksi dan meyakinkan entitas menjalankan good corporate governance. Komisaris yang diproksikan dengan kompetensi dewan komisaris dengan melihat apakah dewan komisaris memiliki pengalaman pada industri yang akan dijalankan, seharusnya komisaris independen yang memiliki pengalaman pada industri yang akan dijalankan lebih memahami industri tersebut. Selain pengalaman, pengetahuan dan teknologi dari industri yang akan dijalankan membuat dewan komisaris lebih mudah melihat peluang dan tren terbaru yang ada didalam perusahaan tersebut. Seharusnya dengan pengalaman yang dimiliki oleh komisaris independen dapat memberikan nilai yang positif untuk meningkatkan integritas laporan keuangan (Oktasiva dkk., 2015).

Pertahanan terhadap pihak investor dalam jangka pendek maupun jangka Panjang untuk memastikan kebijakan yang akan dilakukan entitas dewan komisaris dan direksi mempunyai posisi penting dalam good corporate governance (Wulandari dan Budiartha, 2014). Ada faktor penyebab dewan komisaris tidak melaksanakan pengawasan secara optimal yaitu karena adanya pemegang saham mayoritas yang memiliki peranan yang utama oleh karena itu mengakibatkan dewan komisaris tidak independen pada saat melakukan fungsi pemantauan. Dengan dilakukannya penunjukan dan kehadiran komisaris independen yang ada didalam entitas hanya dilaksanakan untuk mematuhi peraturan dan pemenuhan regulasi pemerintah, tetapi tidak dapat melakukan pengawasan dengan optimal dalam membentuk tata kelola agar bagus Wulandari dan Budiartha (2014). Penelitian dari Tussiana dkk. (2016), dan Wulandari dan Budiartha (2014) selaras dengan penelitian ini yang menunjukan bahwa komisaris independen tidak berpengaruh terhadap integritas laporan keuangan.

\section{Pengaruh Kepemilikan Asing Terhadap Integritas Laporan Keuangan}

Kepemilikan asing dengan jumlah yang besar dan memiliki hak kontrol dipilih untuk mewakili mekanisme pemantauan eksternal, karena investor institusi asing memiliki kemampuan pemantauan yang unggul dalam meningkatkan transparansi dan hak pemegang saham tetapi hal tersebut tidak selalu bahwa kepemilikan mayoritas bisa kontrol yang baik untuk meningkatkan integritas laporan keuangan. Ada dua faktor penyebab kepemilikan asing tidak dapat melakukan pemantauan eksternal dengan baik yaitu pertama, karena kepemilikan asing yang di pemegang oleh asing memiliki asimetri informasi yang memiliki kendala oleh letak geografis sehingga mereka sulit untuk memantau perusahaan dari jauh. Kedua, jika kepemilikan asing dikelola dengan buruk sehingga dapat dikatakan secara aktif risiko manajer menyembunyikan tingkat masalah tata kelola dan kegiatan pengambil alihan seperti memberikan informasi laporan keuangan yang tidak jelas atas pendapatan yang dikelola (Bokpin et al., 2015).

Meskipun kepemilikan asing dianggap menekan perusahaan untuk menjaga laporan keuangannya tetap bersih, penelitian ini selaras dengan penelitian yang dilakukan oleh Malau dan Mulianingsari (2018) menunjukan kepemilkan asing tidak berpengaruh terhadap integritas laporan keuangan.

\section{Pengaruh Audit Tenure Terhadap Integritas Laporan Keuangan}

Audit Tenure adalah lamanya masa seorang auditor yang bekerja dalam suatu perjanjian (Qoyyimah dkk., 2015). Orang yang mengevaluasi kelaziman atas laporan keuangan auditor independen, untuk menaikan kualitas dan kejujuran informasi laporan keuangan perusahaan maka akuntan publik memiliki posisi yang berguna (Arista, 2018). Audit tenure disebut juga masa kerja auditor dengan klien di Indonesia Peraturan Pemerintah Indonesia no.20 tahun 2015 pada tanggal 16 April 2015 tentang praktik jasa akuntan publik sudah diatur. Isi peraturan tersebut yaitu batasan auditor paling lama 5 tahun buku bertubi-tubi masa kerja dan bisa memberikan jasa audit kembali terhadap 
Audit, Ownership Financial

Statement Integrity suatu entitas sesudah 2 tahun buku bertubi-tubi tidak memberikan jasa audit. Ikatan yang tidak terlalu lama antara auditor dan klien bisa berkemampuan untuk meningkatkan independensi auditor dan juga mutu audit sehingga meningkatkan integritas laporan keuangan, peran auditor adalah menilai laporan keuangan telah dirangkai berdasarkan SAK dan prinsip kewajaran bebas dari salah material berdasarkan signaling theory.

Ikatan yang lama antara auditor dan klien bisa membujuk auditor dalam memberikan opini. Oleh karena itu harus dilakukan pergiliran auditor yang bisa meningkatkan mutu audit dalam proses laporan keuangan (Arista dkk., 2018). Audit tenure biasanya dikaitkan dengan pengaruhnya terhadap independensi auditor, dua faktor yang memicu ikatan yang buruk antara auditor dan klien dengan mutu audit yaitu menurunnya independensi yang timbul dengan berkembangnya ikatan pribadi dan kurangnya daya tampung auditor dalam memberikan pengevaluasian atas kesalahan-kesalahan (Himawan dan Mulianingsih, 2017). Oleh karena itu independensi auditor harus dijaga dengan adanya pergantian auditor sehingga meningkatkan integritas laporan keuangan. Penelitian ini juga selaras dengan penelitian dari Amrulloh dkk. (2016), Himawan dan Mulianingsih (2017), dan Prananti (2018) menunjukan bahwa audit tenure berpengaruh terhadap integritas laporan keuangan.

\section{PENUTUP}

Komite audit berpengaruh negatif terhadap integritas laporan keuangan, ini menunjukan bahwa hipotesis pertama diterima. Komisaris independen tidak berpengaruh terhadap integritas laporan keuangan, ini menunjukan bahwa hipotesis kedua ditolak. Kepemilikan asing tidak berpengaruh terhadap integritas laporan keuangan, ini menunjukan hipotesis ketiga ditolak. Audit tenure berpengaruh positif terhadap integritas laporan keuangan, hal ini membuktikan hipotesis keempat diterima. Hasil penelitian menunjukan bahwa jika hubungan auditor dan klien singkat bisa menjaga independensi audtor sehingga bisa menaikan integritas laporan keuangan.

Beberapa rekomendasi yang diharapkan bisa bermanfaat untuk penelitian selanjutnya:

a. Untuk investor jika akan menggunakan laporan keuangan yang akan dijadikan alat untuk melihat kehandalan laporan keuangan harus menganalisis terlebih dahulu sebelum nantinya akan dijadikan pertimbangan untuk melakukan investasi.

b. Untuk perusahaan agar lebih memperhatikan faktor pengaruh integritas laporan keuangan apa saja agar kedepennya lebih bisa memberikan laporan keuangan yang berintegritas, sehingga untuk peneliti selanjutnya diharapkan proporsi untuk komisaris independen bisa menggunakan partisipasi dewan komisaris agar bisa meningkatkan laporan keuangan berintegritas pada perusahaan manufaktur.

c. Untuk peneliti selanjutnya dapat menambah periode penelitian agar dapat menambah sampel untuk diteliti, dapat menambah mekanisme tata kelola perusahaan seperti kepemilikan institusional dan kepemilikan manajerial, dan juga dapat menambah variabel independen lain seperti market pricing accrual untuk mempengaruhi integritas laporan keuangan.

\section{DAFTAR PUSTAKA}

Amrulloh, Putri, Wirama. (2016). Pengaruh Mekanisme Corporate Governance, Ukuran KAP, Audit Tenure dan Audit Report Lag pada Integritas Laporan Keuangan. EJurnal Ekonomi dan Bisnis. 5(8):2305-2328.

Arista S, Wahyudi T, Yusnaini Y. (2019). Pengaruh Struktur Corporate Governance Dan Audit Tenure Terhadap Integritas Laporan Keuangan. AKUNTABILITAS Jurnal Penelitian dan Pengembangan Akuntansi. 12(2):81-98. doi:10.29259/ja.v12i2.9310

Bursa Efek Indonesia. (2020). Laporan Keuangan Tahunan. Diakses 03 maret 2020,https://www.idx.co.id/perusahaan-tercatat/laporan-keuangan-dantahunan/.

Bokpin, G.A., Isshaq Z., \& Nyarko, E.S. (2015). Corporate Disclosure And Foreign Share Ownership: Empirical Evidence From African Countries, International 
Journal Of Law And Management, Vol. 57 No. 5, DOI 10.1108/IJLMA-01-20140004.

DANIAL, M., PENGARUH SISTEM PENGENDALIAN INTERN PENJUALAN TERHADAP EFEKTIVITAS PENJUALAN.

Eksandy. (2017). Pengaruh Ukuran Perusahaan, Solvabilitas, Profitabilitas Dan Komite Audit Terhadap Audit Delay (Pada Perusahaan Proferti Dan Real Estate Yang Terdaftar Di Bursa Efek Indonesia Pada Tahun 2012-2015. Competitive Jurnal Akuntansi Dan Keuangan, Vol.1, No. 2. E-ISSN 2549-791X.

Givoly D, Hayn C. (2000). The Changing Time-Series Properties of Earnings, Cash Flows and Accruals. Journal of Accounting and Economics. 29:287-320.

Hardiningsih, P. (2010). Pengaruh Independensi, Corporate Governance Dan Kualitas Audit Terhadap Integritas Laporan Keuangan, Kajian Akuntansi, Volume 2 No.1, 67-76.

Hoesada J, Pradika E. (2019). Integrity of Financial Statement: Big and Independent Are Not Guarantee. Journal Accounting Finance Auditing Studies, 5(1):59-79. doi:10.32602/jafas.2019.3.

Himawan F.A., Mulianingsih I. (2017). Pengaruh Audit Tenure, Mekanisme Corporate Governance Terhadap Integritas Laporan Keuangan, Esensi, Volume 20 No. 2, Hlm $1-24$.

Indrasari A, Yuliandhari WS, Triyanto DN. (2017) Pengaruh Komisaris Independen, Komite Audit, Dan Financial Distress Terhadap Integritas Laporan Keuangan. Jurnal Akuntansi, 20(1):117. doi:10.24912/ja.v20i1.79

Irawati L, Fakhruddin I. (2016). Pengaruh dan Kualitas Audit Corporate Governance terhadap Integritas Laporan Keuangan. Kompartemen, 14(1):90-106.

Istiantoro I, Paminto A, Ramadhani H. (2018). Pengaruh Struktur Corporate Governance terhadap Integritas Laporan Keuangan Perusahaan pada Perusahaan LQ45 yang Terdaftar di BEI. Akuntabel. 14(2):157. doi:10.29264/jakt.v14i2.1910.

Jensen, M.C. \& Meckling, W.H. (1976). Theory Of The Firm: Managerial Behavior, Agency Costs And Ownership Structure, Journal Of Financial Economics, Page 1-56.

Kusmayadi, D., Rudiana, D. \& Badruzaman J. (2015). Good Corporate Governance. LPPM Universitas Siliwangi: Tasikmalaya.

Malau M. (2018). The Effect Of Market Pricing Accrual, Foreign Ownership, Financial Distress, And Leverage On The Integrity Of Financial Statements. Economic Annals. LXIII (217):129-139.

Miko NU, Kamardin H. (2015). Impact of Audit Committee and Audit Quality on Preventing Earnings Management in the Pre- and Post- Nigerian Corporate Governance Code 2011. Procedia and Behavioral Sciences. 172:651-657. doi:10.1016/j.sbspro.01.415.

Nurdiniah D, Pradika E. (2017). Effect of Good Corporate Governance, KAP Reputation, Its Size and Leverage on Integrity of Financial Statements. Int $J$ Economic Finance Issues. 7(4):174-181.

Oktosiva, F., Theresia, M., Hidayat, A. (2015). Pengaruh Independensi, Kompetensi, Dan Partisipasi Dewan Komisaris Terhadap Kinerja Keuangan Perusahaan, Studi Akuntansi \& Keuangan Indonesia, Hlm 210-231.

Peraturan Otoritas Jasa Keuangan Nomor 30/PJOK.05/2014 Tentang Tata Kelola Perusahaan Yang Bagi Perusahaan Pembiayaan. . Peraturan Pemerintah Republik Indonesia Nomor 20 Tahun 2015 Tentang Praktik Akuntan Publik.

Prananti P.C. (2018). Factors Affecting Integrity Of Financial Statements In Manufacturing Companies Listed In Indonesia Stock Exchange, RJOAS, https://cyberleninka.ru/article/n/factors-affecting-the-integrity-of-financialstatements-in-manufacturing-companies-listed-in-indonesia-stock-exchange. 
Audit, Ownership

Financial

Statement Integrity

$\underline{348}$
Qonitin R.A., Yudowati S.P. (2018). Pengaruh Mekanisme Corporate Governance Dan Kualitas Audit Terhadap Integritas Laporan Keuangan Pada Perusahaan Pertambangan Di Bursa Efek Indonesia, Assets, Volume 8 N.10, Hlm 167-182.

Qoyyimah S.D., Kholmi M., Harventy G. (2015). Pengaruh Struktur Corporate Governance, Audit Tenure Dan Ukuran Kantor Akuntan Publik (KAP) Terhadap Integritas Laporan Keuangan, Jurnal Reviu Akuntansi Dan Keuangan, Volume 5 No.2, Hlm 1-10.

Savitri E. (2016). Corporate governance mechanism and the moderating effect of independency on the integrity of financial reporting. Investment Management Financal Innovations. 13(4):68-74. doi:10.21511/imfi.13(4).2016.06.

Shan YG, Graves C, Ali HH. (2013). Effect of board composition and ownership characteristics on fraud Evidence from Malaysian listed companies. South East Asia Research. 21(2):323-342. doi:10.5367/sear.2013.0149.

Siahaan SB. (2017). Pengaruh Good Corporate Governance dan Kualitas KAP terhadap Integritas Laporan Keuangan Studi Kasus pada Perusahaan Manufaktur yang terdaftar di Bursa Efek Indonesia. Akuntansi dan Keuangan Methodist. 1:81-95.

Siregar, S. (2017). Metode Penelitian Kuantitatif Dilengkapi Dengan Perbandingan Perhitungan Manual \& SPSS, Cetakan ke 4, Kencana: Jakarta.

Spence M. (1973). Job Market Signaling. Q J Econ. 87(3):355. doi:10.2307/1882010.

Wulandari N, Budiartha I. (2014). Pengaruh Struktur Kepemilikan, Komite Audit, Komisaris Independen Dan Dewan Direksi Terhadap Integritas Laporan Keuangan. E-Jurnal Akuntansi. 7(3):574-586.

CNBC Indonesia. (2019). Diakses 06 maret 2020. https://www.cnbcindonesia.com/market/20190329075353-17-63576/tiga-pilardan-drama-penggelembungan-dana.

Tempo.Co (2018). Diakses 07 maret 2020. https://otomotif.tempo.co/read/1148326/hasil-investigasi-nissan-sebut-kasuscarlos-ghosn-bisa-meluas. 